\title{
Management innovation made in China: Haier's Rendanheyi
}

Jędrzej George Frynas, Open University Business School, UK

Michael J. Mol, Copenhagen Business School, Denmark

Kamel Mellahi, Warwick Business School, University of Warwick, UK

\section{Accepted for publication in:}

California Management Review, vol. 61, no. 1, 2018

\begin{abstract}
This article shows how emerging market companies like China's Haier Group create management innovations that are appropriate for an environment characterized by increased volatility, uncertainty, complexity, and ambiguity (VUCA). Dealing with VUCA effectively requires practices favoring nimble and decentralized responses; the Haier Group developed a platform of management practices under the label Rendanheyi (in Chinese: 人单合一) to transform itself from a conventional hierarchical manufacturing firm into a highly responsive online-based entrepreneurial company with "zero distance to the customer". We demonstrate how the organizational, competitive, institutional, and technological contexts mattered for the development of Rendanheyi. Our study contributes several insights for practitioners and academics. First, we showcase how context dependent management innovations are created to allow emerging market firms like Haier to deal with a high VUCA world. Second, we draw lessons from Haier's experimentation process for other firms. Finally, we create an extended process model of management innovation that managers, in both emerging and developed countries, can readily apply.
\end{abstract}

\section{Keywords}

management innovation, VUCA, emerging markets, China, Haier 
Emerging market companies face a challenging environment, characterized by increased volatility, uncertainty, complexity, and ambiguity (VUCA). ${ }^{1}$ Volatility comes from, among others, varying growth rates and currency fluctuations, making the business environment unstable and unpredictable. Fluid market conditions, the impact of new technologies on organizational structures, and the unresolved future of international trade rules create uncertainty. Foreign investments, including in developed countries, imply more complex environments. And there is significant ambiguity, for instance around the effects of maintaining existing home-grown management practices, like relationship-based management in Asia, versus adopting Western theories and management practices ${ }^{2}$. But some companies such as China's Haier Group, the world's largest white goods company, have taken on this challenging environment by reinventing themselves and developing a management model that thrives in such a high-velocity environment.

In this article we show how companies like Haier create management innovations in a high VUCA context. Management innovation involves the creation of new management practices. ${ }^{3}$ Under the leadership of Zhang Ruimin, the Haier Group developed "Rendanheyi" (in Chinese: 人单合一), which can be loosely translated as “integration of people and goals" or "the win-win model of individual-goal combination". Rendanheyi is a platform made up of a bundle of management practices, rather than a single new practice. Other such platforms have, of course, evolved historically; for example, Toyota's lean manufacturing has an overall goal to produce on a large scale with minimum effort and waste - and encompasses several specific practices including just-in-time, Kanban, and target costing. ${ }^{4}$ Similarly, Rendanheyi is intended to be an integrated and all-encompassing management model with the overall goal to create "zero distance to the user" and unleash entrepreneurial autonomy within the organization. Specific elements of the Rendanheyi platform include autonomous micro-enterprises, performance-based compensation and open online user platforms. 
From the introduction of Rendanheyi in 2005, Haier was transformed from a conventional hierarchical appliance manufacturer into a highly responsive, diversified onlinebased entrepreneurial conglomerate organized as entirely autonomous micro-enterprises. During 2005-2009, Haier operated newly established strategic business units and implemented new IT solutions and performance-based measures to better connect the company to customers. In 2010, micro-divisions called ZZJYT (an abbreviation for "zi zhu jing ying ti", translated as independent operating unit) were established. ZZJYTs operated like a virtual team and each ZZJYT leader had considerable decision-making autonomy, and new performance-based measures were introduced. ${ }^{5}$ In 2014, Haier was eventually transformed into a conglomerate of independent micro-enterprises called "xiaowei qiye" (abbreviated as "xiaowei"), operating as independent companies with ownership stakes from outsiders and responsible for all contracting, budgeting and recruitment decisions. This latest phase has been labelled "Rendanheyi 2.0".

The case of Rendanheyi is of enormous importance for management innovators, as it demonstrates how a high VUCA context in an emerging market can shape novel management practices. In the literature there has been renewed interest in management innovations in recent years $^{6}$, but few studies have explored their initial creation process ${ }^{7}$, and here we focus on this so-called "management innovating". In this article we tackle a major shortcoming of the existing literature which revolves around the Birkinshaw et al. model of "management innovating", which is that it largely neglects the role of context. ${ }^{8}$ As we will demonstrate, the organizational, competitive, institutional, and technological contexts mattered a lot in the Haier case.

Our study contributes several insights for practitioners and academics. First, we showcase how context dependent management innovations are created to allow emerging market firms like Haier to deal with a high VUCA world. Second, we draw lessons from Haier's 
experimentation process for other firms. Finally, we extend the process model of management innovation that managers, in both emerging and developed countries, can readily apply.

\section{The state of knowledge on management innovation}

Firms have long recognized the importance of technological innovations in products and processes, but increasingly also value the competitive edge from innovation in how the firm is managed. Historical examples of such "management innovations" include advances in structure like the (divisional) M-form at General Motors, but also tools and techniques like the balanced scorecard (Analog Devices) and scenario planning (Shell). Most academic writing is focused on the ways in which existing management practices spread across a population of organizations and from one industry or country to the next. ${ }^{9}$ While these are interesting questions, they do not help to understand the process of developing a novel management innovation such as Rendanheyi.

Still, some work looks at what drives organizations first to invent and then to implement new management practices, i.e. management innovating. A major advance in understanding management innovating came from the Birkinshaw et al. process model, which offers a template to understand how management practices are created and implemented. ${ }^{10}$ In a nutshell, this model focuses on understanding the active role of individuals, who are called internal and external change agents, in different phases of management innovating.

Internal change agents are, of course, crucial in understanding why and how a specific management innovation comes about. Indeed, all management innovations can be linked to a powerful protagonist. For example, the founder of Toyota Motor Corporation Kiichiro Toyoda and production engineer Taiichi Ohno played key roles in the development of lean

manufacturing at Toyota. ${ }^{11}$ Much more recently, the Chairman of the Samsung Group Kun-Hee 
Lee was crucially involved in developing the co-opetition model within Samsung. ${ }^{12}$ In addition, external change agents such as gurus and management consultants can be involved in management innovating.

The Birkinshaw et al. process model proposes that there are four distinct phases in management innovating. The first of these comes about when change agents are motivated to consider creating a management innovation because of some dissatisfaction with the status quo. The second stage, invention, occurs when a thought or real experiment is started to create a new hypothetical management practice. In the third stage, implementation, this hypothetical practice is put into practice to establish its value. Finally, in the fourth stage, theorization and labeling, there is retrospective sensemaking whereby an innovation can receive legitimacy. Thus we understand relatively well what actions agents undertake to create management innovations.

Yet a shortcoming of this model and the bulk of management innovation literature is that it mostly black boxes the role of context, even though context clearly matters for the development of management innovations. For example, the development of lean manufacturing at Toyota benefited from the context of Japan, with its different cultural understanding of time as a simultaneous rather than sequential process, its traditionally close collaborative arrangements between manufacturing firms and suppliers within zaibatsu/keiretsu, but also post-war material shortages. ${ }^{13}$ And the development of the co-opetition model was supported by Samsung's common language, organizational culture and management systems, which fostered close collaboration across the Samsung Group and thus helped towards seizing new business opportunities and reducing transaction costs. ${ }^{14}$

Context consists of the wider environmental context, "the broad set of stimuliexogenous to the focal organization - that shape the management discourse" (e.g. Toyota's Japanese context) and the organizational context, "the administrative and social mechanisms that management can manipulate to shape the behaviors of actors in the organization" (e.g. 
Samsung's organizational culture and management systems). Birkinshaw et al. argue that 'these two aspects of context potentially influence all activities associated with management innovation', but never provided further detail of what these contexts might actually consist of. ${ }^{15}$ In other words, how context influences management innovating largely remains a mystery in the management innovation literature.

Still, other work has provided insights into the aspects of environmental and organizational context that we can draw from. In the environmental context, the nature of a country's institutions, like its laws, corporate governance systems, and national culture, plays an important role in shaping what kinds of management innovations emerge and when. ${ }^{16}$ But technology is also known to be an important factor, as it offers new opportunities, ${ }^{17}$ as does the presence of competitive pressure, which may force a firm to innovate. ${ }^{18}$ In terms of the organizational context, important factors to consider for the successful implementation of management practices are a firm's leadership, especially from the top, fit with the existing structure, and presence of resources, including the right kind of organizational culture. ${ }^{19}$

To advance knowledge on management innovating, our contribution here is to help understand how the environmental and organizational contexts affect management innovating in an emerging market multinational characterized by VUCA. An answer to this question raises the intriguing possibility that the sources of competitive advantage of Chinese and other emerging market multinationals may not just lie in cost advantages, or even the ability to come up with innovative products, but also in innovative management practices.

Our research on Rendanheyi presented below suggests that both the organizational context and the environmental context contributed greatly to management innovating at Haier. Furthermore, once we start to unpack the two types of context three key factors emerge for each type. In the organizational context we found that structure, leadership and resources were all clearly connected to the management innovation process. And in the environmental context, we 
observed the influences of competitive, technological, and institutional aspects of the environment. Eventually leadership turned out to be the most important of these factors. Figure 1 below captures the overall model.

\section{Figure 1 about here}

Our research on Haier is based on personal interviews with senior executives (including the Haier Group chairman) and owner-CEOs of xiaowei (micro enterprises) involved in the design and implementation of Rendanheyi, as well as external consultants and experts who advised senior executives on the company's restructuring. We travelled to the Haier Group headquarter in Qingdao where we conducted most of the interviews. We also conducted a tour of the company's Qingdao site and attended a symposium dedicated to Rendanheyi in Beijing. Finally, we consulted internal and external documents to supplement these observations. We now discuss the conditions that gave rise to Rendanheyi and the process through which it was developed and diffused throughout the organization to boost innovation and to embrace new business opportunities.

\section{Rendanheyi: Creating responsive online-based entrepreneurial units}

\section{The making of the Haier Group}

Like other leading Chinese manufacturing firms, Haier has become an effective competitor of Western firms over the last decade and a half. But Chinese firms are not known for inventing radical modern management practices. In particular, Chinese management practices are said to maximize efficiency and fast commercialization, and innovative firms from China are said to "excel at cost reduction, accelerated product development and networked

production". ${ }^{20}$ This suggests the Chinese management focus may well support product 
development and production activities, but is unlikely to support creativity and management innovation. So how was Rendanheyi developed and why did it make sense for Haier to invent it?

The Haier Group began as a nearly bankrupt refrigerator company called Qingdao General Refrigerator based in Qingdao, a city in China's coastal Shandong province. In 1984, a young municipal official Zhang Ruimin, was appointed as plant director and he has remained the company's chairman until today. Zhang Ruimin had a zeal for improvement from the start. Already in 1984, he introduced technology and equipment from the German company Liebherr to produce refrigerators. In 1990, the company started exports to Europe as a contract manufacturer for multinational brands. Chairman Zhang said: "We started exporting to developed markets first because if your products are good enough for consumers in Europe and in the US, you will have better products in developing markets". In 1992, the company was renamed into the Haier Group.

Chairman Zhang began to focus Haier's attention around key beliefs that have sustained its management innovating ever since: continuous external environmental change requires continuous internal change; customer service, not existing products, was key to maintaining Haier's forward motion; price competition would ultimately be destructive; Haier needed to offer more, not less, to China's increasingly sophisticated customers; the secret of what Haier could offer the customer lay in the knowledge of Haier' s employees; all too often, an existing organization structure constrained, rather than liberated, employee talent; only by making the "employment agreement" equitable to all who are affected by it (customers, organization, and employees), could a powerful incentive engine be constructed to drive continuous change. Haier's story can be seen in episodes, eras, or chapters, but above all it is a continuing singular story of monotonically consistent change. 
By the 1990s, Haier acquired many other Chinese companies. The product range expanded beyond refrigerators to include home appliances such as washing machines, televisions, air-conditioners and telecommunications equipment. The company improved its products by acquiring foreign technology through joint ventures and strategic alliances with companies such as Mitsubishi of Japan and Merloni of Italy. Zhang Ruimin was once quoted: "First we observe and digest. Then we imitate. In the end, we understand it well enough to design it independently". ${ }^{21}$ By 1998, the Haier Group had a market share of over $30 \%$ in refrigerators, washing machines and air-conditioners in the Chinese market.

However, the Chinese home appliances market was saturated, while the Chinese government encouraged Chinese enterprises to expand internationally. Furthermore, Haier faced greater domestic competition, as foreign companies began to expand aggressively in the Chinese market. Therefore, the Haier Group began setting up operations overseas, including in the United States (1999), Italy (2001) and Germany (2001). It emulated the strategies of successful Japanese and Korean firms such as Sony, Samsung and LG in terms of taking its own brand to foreign markets and in terms of establishing production as well as R\&D in Western countries. By the mid-2000s, Haier was an established, successful global brand.

\section{The making of Rendanheyi}

Not satisfied with past achievements, Haier's senior management had the ambition to become the global industry leader and to create a truly innovative global company that competes on the basis of new product innovations. In 2005, Yang Mianmian, group president at the time, said: "We are number three in the world for white goods, we want to be number one". ${ }^{22}$ Around that time, Zhang Ruimin first used the word "Rendanheyi", which was aimed at achieving (in Zhang's words) "zero distance to the customer", whereby the entire corporate structure is 
dedicated to serving customers, giving them personalized products and services, by creating independent entrepreneurial units that operate as quasi small independent firms (within the boundaries of the company) and have market relationships among themselves.

Key to the development of Rendanheyi was the spirit of curiosity and experimentation that originated with Zhang Ruimin - the central change agent. Rendanheyi essentially includes a collection of organizational practices that have evolved over time (see Table 1 for Rendanheyi's key characteristics). From 2005, Haier went through a ten-year period of intensive experimentation with organizational structure and performance management. During 2005-2009, Haier established strategic business units and implemented new IT solutions and performance measures to connect the organization to customers. In 2009, Haier announced its strategic transformation from being exclusively a manufacturing company to becoming a service-oriented company, meaning that it considers manufacturing as only one means of satisfying customer needs.

In 2010, Haier established the first ZZJYT, which operated like a virtual team (i.e., its offices were not necessarily physically close) with typically 10 to 20 employees from different functional and hierarchical levels, brought together for the project. ZZJYTs enjoyed operational autonomy, including recruiting employees for the team, setting compensation rules and determining bonus payments. But Zhang Ruimin was not satisfied with the performance of ZZJYTs, as he felt that it presented (as he put it to us) "a closed mechanism", without sufficient involvement of outsiders, and hindering faster entrepreneurial development, because employees were still paid a basic salary (even though bonuses were added to it) and lacked sufficient autonomy.

In 2014, the entire corporate structure was therefore re-organized, breaking the organization into a network of independent micro-enterprises called 'xiaowei' to replace the ZZJYT. The owner-CEO of a xiaowei (typically 6-8 members, but it can be larger) has a small 
ownership stake (some xiaowei are majority Haier-owned, but some xiaowei are not and Haier is currently requiring "continuous dilution" of its holdings) and operates as an entrepreneur with absolute autonomous decision-making (including all contracting, budgeting and recruitment decisions). The performance of xiaowei is measured against a combination of financial KPIs and user value added. The remuneration of xiaowei members no longer depends on a salary and is entirely tied to performance. Going beyond the ZZJYT, the xiaowei leader has total autonomy, like a CEO of an independent company, and is not subject to headquarter approval of any decisions. A xiaowei is not forced to use internal suppliers. Furthermore, the xiaowei are actively encouraged to seek the involvement of external partners and partial external funding for projects.

The xiaowei naturally vary greatly in terms of their function. Around 200 xiaowei are direct user-facing micro-enterprises developing, for example, new white goods products, entirely new products such as water purification equipment and a tablet, or financial products. They actively use a myriad of online platforms with millions of customers participating in the process of designing, producing and using Haier products, while keeping the platforms open to external entrepreneurs to join as partners. Most of the other xiaowei are "node microenterprises", which provide products and services to user-facing micro-enterprises, for example, xiaowei of road transport providers and supply chain xiaowei of factory workers.

The corporate headquarter provides support for all of these xiaowei, allocates corporate resources and sets the strategic direction for the entire organization. The corporate headquarter fulfills the conventional strategy-setting headquarter functions and provides corporate services such as HR and marketing through dedicated platforms but it is also partly organized as a xiaowei, for example, the corporate legal team operates as a xiaowei that can draw up standard contracts between other micro-enterprises for a fee, while a xiaowei of the communications 
department develops a cartoon series to help increase merchandise sales and generate additional revenues (Table 2 contains a simplified organizational structure).

Table 1 and Table 2 about here

The latest iteration of Haier's management practice has been labelled "Rendanheyi 2.0" and is close to Zhang Ruimin's vision of Haier's organizational form in the $21^{\text {st }}$ century. Rendanheyi is therefore a platform management innovation, i.e. it contains a number of specific, interrelated practices. In a historical perspective, this is a logical third phase in Haier's development as a management innovator. In the first phase, prior to Rendanheyi, the company primarily copied management practices developed elsewhere such as Business Process Engineering, with varying degrees of success. In the second phase, Rendanheyi 1.0, the company first created some of its own stand-alone management practices. Now, with Rendanheyi 2.0, Haier is successfully creating a number of inter-linked practices. Haier is likely to continue to create specific new practices under the Rendanheyi platform.

It may be somewhat premature to discuss the effectiveness of Rendanheyi, in particular the effectiveness of xiaowei that have only been in existence since 2014. But the success of Rendanheyi can possibly be gleaned from Haier's growth in profit margins. When Rendanheyi was first introduced in 2005, Haier Group's profit margins were estimated at below 3-4\% compared with 6-8\% for rivals such as Whirlpool. In 2015, the net profit margin of Qingdao Haier Co. Ltd. (one of two listed Haier Group companies) was 5.7\% compared with Whirlpool Corp.'s 3.9\%. And with Rendanheyi 2.0, Haier Group's profits increased $12.8 \%$ to 20.3 billion yuan (ca. US\$ 2.9 billion) between 2015 and 2016, while the group's revenue rose $6.8 \%$ to 201.6 billion yuan (ca. US\$29.3 billion). A key element of Rendanheyi 2.0 have been the internet platforms that connect Haier with its users - the volume of transactions on such platforms rose $73 \%$ to 272.7 billion yuan (ca. \$39.6 billion) between 2015 and 2016 . 
Nonetheless, Haier has largely been unable to diffuse Rendanheyi across its global subsidiaries. In the United States, for example, larger micro-divisions called "platforms" have been created instead of xiaowei, and - in contrast to xiaowei in China - for example, every employee was part of several platforms and remuneration was not entirely based on platform performance. In Russia, the top management team formed a xiaowei along the Chinese xiaowei lines, however, rank-and-file employees continued to work in a hierarchical organization without forming ZZJYTs or xiaowei. Low adoption levels outside China raise important questions about the applicability of Rendanheyi in different national contexts, which underlines the importance of understanding how context matters for management innovations.

\section{How context mattered to Haier's Rendanheyi}

In our research on Haier's creation of Rendanheyi we used the six categories mentioned earlier, i.e. three categories in the environmental context and three categories in the organizational context.

\section{Environmental context}

The three categories of environmental context our research brought up are the competitive, technological, and institutional environments - all of which are characterized by increasing VUCA forces that have affected the development of Rendanheyi.

\section{Competitive}


Haier has been operating in a VUCA environment for over a decade. The competitive environment for Haier has become more uncertain since the early 2000s. Foreign rivals such as Panasonic, Sanyo, Whirlpool, Bosch-Siemens and Electrolux already entered the Chinese market in the 1980s and 1990s. But it was in the early 2000s that Chinese white goods manufacturers came under considerable competitive pressure from foreign competitors in the Chinese market. In December 2001, China formally joined the World Trade Organization (WTO) and opened the white goods sector to competition. The previous sales quotas on white goods were scrapped, and foreign manufacturers were allowed to also engage in distribution and service activities in the Chinese market. The most important foreign home appliance brands (with the notable exception of GE) started manufacturing and R\&D activities in China. Whirlpool (which previously withdrew from China) re-entered the Chinese market in 2002 through strategic partnerships with local firms Gome and Suning, while other foreign rivals also expanded their presence in China.

With increased volatility from domestic competition, Chinese white goods firms experienced production overcapacity for the first time as the market share of foreign firms in refrigerators quickly went up from $26 \%$ to $31 \%$, and in washing machines from $31 \%$ to $38 \%$ within a year. A fierce price war broke out. Domestic competition from foreign rivals and lower margins pushed Haier to expand globally to counter foreign rivals on their home turf in the United States and Europe. In anticipation of China's WTO membership, Haier opened manufacturing and R\&D centers in Italy and Germany (2001) and established a US factory (2002).

As Haier became a truly global company with presence in over 100 countries, it faced a more complex environment comprising of many different markets, all with unique market characteristics and consumer preferences. It also faced further uncertainty due to slower demand and greater competition amidst the global recession and a sharp decline in China's 
property market. Haier's senior management believed that its workers were not productive enough compared with global competitors.

The development of Rendanheyi 2.0 coincided with slower growth rates in China's economy, which declined in each consecutive year from $10.6 \%$ in 2010 to $6.9 \%$ in 2015 , while total investment in China's economy declined from 47.9\% of GDP in 2010 to $44.7 \%$ in $2015 .^{23}$ As an additional burden, the value of the Chinese currency has steadily appreciated, from 8.2765 yuan per US\$ to 6.1248 yuan per US\$ between the start of 2005 and the start of 2015 .

There were also signs that the white goods sector would become more consolidated. In 2005, Whirlpool acquired Maytag, once considered one of the most admired premium brands. China's entry into the WTO and greater global competitive uncertainty persuaded Zhang that Haier needed to reinvent itself and become a user-oriented organization. Today we know that fears about global consolidation were justified as a merger wave has swept through the white goods industry. In 2016, Whirlpool purchased Indesit, Midea bought Toshiba's white goods business, Arçelik took over Dawlance, Bosch bought out its partner Siemens, and in 2017, Haier completed a US\$ 5.6 billion takeover of GE's white goods business. Competitive pressures were therefore also a driver for Haier to start introducing Rendanheyi.

\section{Technological}

The white goods sector was traditionally a slow-moving, mature industry. But there was increasing ambiguity about the directions for future consumer demand, amidst booming ecommerce, demand for niche products and a shift towards a customized user experience. Zhang Ruimin was an early web enthusiast. When he conceived his early ideas on Rendanheyi around 2005, he assumed that the Internet would change the relationship between companies and customers. Zhang recognized that the internet brought about (in his own words) "zero-distance 
access to information", meaning customers can get information more quickly than companies. In his view, this required a shift from mass production to mass customization. When the ZZJYT model was introduced around 2010, Zhang developed a vision of complementary physical and virtual networks and envisaged that Haier's online platforms should be used as vehicles for close collaboration with users to develop new products and to provide a customized user experience.

Chairman Zhang was influenced by authors such as Don Tapscott and Jeremy Rifkin, who painted a picture of communications-driven technological revolutions in the business world. ${ }^{24} \mathrm{He}$ invited many such authors to visit Haier in the Qingdao headquarters. When the "Maker Movement" (related to digital fabrication) surfaced, Zhang Ruimin invited the editorin-chief of Wired Magazine Chris Anderson in for talks and workshops, identifying everyone as a "maker" on their business cards and job-description. Zhang became convinced that technology will fundamentally alter the basis of competition in future, moving from competition between close-ended hierarchical companies towards competition between open online platforms, which can link companies with users and external partners to jointly create value. One of Zhang Ruimin's favorite quotes is "the world is your R\&D department", which suggests that $R \& D$ resources can be acquired through collaboration with users, through collaboration with external partners or through purchases from third parties. He made a distinction between a traditional "customer" for a one-time money transaction, and a "user" for continuous interaction and participation. Zhang wanted to create a community of users.

Zhang Ruimin also observed technological advancements made by other companies. He was particularly impressed by Apple's iPad, which became "magical” once app designers were invited in to populate the iPad boxes with their ideas, and once Apple's customers could personalize their iPads with the variety of apps becoming available, in the process transforming each iPad into a truly unique device. Zhang argued that the iPad was a "platform" for expressing 
and realizing the dreams of other ecosystem players - app designers and users - and that Haier could similarly be transformed into a platform for the dreams of others, and, in the process, would become faster, more open, and without boundaries.

Consequently, in December 2012, Haier formally announced that it was "entering the networking stage”. On the open platforms that Haier has created as part of developing Rendanheyi 2.0, customers are involved in designing products, through discussing product features, product uses, accessories, and potential innovations. These online platforms naturally greatly vary in size and scope, but - as pointed out elsewhere ${ }^{25}$ - they have no organizational boundaries so that different teams of specialists and even former competitors and other partners can join a platform, and can draw on considerable resources to unleash entrepreneurial talent and better connect with customers. For example, Haier's online platform for smart-ovens has created an online community of oven users, who communicate, exchange cooking recipes, and exchange ideas on ingredients, hence oven customers have strong personal incentives for using the platform and, in the process, they provide a wealth of feedback to the relevant Haier microenterprises. As another example, Haier created an online water purification platform that allows users to order a test of the water quality at their home and subsequently Haier offers the user suitable water purification solutions - prior to the establishment of this platform, Haier struggled to sell its newly developed water treatment technology; the platform allowed the Haier micro-enterprise to significantly increase sales and to attract substantial venture capital.

Systematic interactions with users and partners on Haier's platforms directly led to the development of an eclectic mix of new products ranging from a Haier mini washing machine for washing children's clothes to new financial products such as the Hongsheng egg-platform for financing egg farms. Against this background of substantial technological transformations Rendanheyi resolved/reduced the impact of ambiguity surrounding the directions for future consumer demand and helped towards realigning technologies and management practices. 


\section{Institutional}

China's institutional context was not entirely conducive to the sort of transformation of the workplace that was required by Rendanheyi. In order to tackle the VUCA environment, Zhang believed that Haier needed to overcome several institutional rigidities and change some of the well-entrenched practices that were perceived to be no longer appropriate or effective. At the core of this transformation was to ask employees to take ownership of their work and become more entrepreneurial. This was a major departure from the traditional top down approach dominating Chinese organizations. A former adviser to Zhang told us that taking ownership is "not a breakthrough concept in Western management, but in Chinese management is really a new concept". The Chinese educational system emphasized conformity and uniformity, producing employees who are used to wait for orders and are relatively passive. Zhang recalled that it was difficult for employees in 2005 to accept that Haier needed "a transformative process not only for our mindset, but more importantly, for our managerial and organizational structure". In fact, in ten years after the launch of Rendanheyi in 2005, over 20,000 employees left Haier because they did not or could not buy into the new management system. So it seems like employees have self-selected to be part of this set of management practices.

At the same time though, China's institutional context was conducive to a company that wanted to rapidly transform itself. There is a vibrant entrepreneurial culture in China. On the one hand, this was facilitated by the Chinese government policy's push for entrepreneurship to become one of the key driving forces for the economy and encouraging and facilitating entrepreneurial activities. ${ }^{26}$ On the other hand, collectivist societies such as China provide a suitable context for entrepreneurship. In such societies, the feeling of social inclusiveness, 
collective accountability as well as reliance on social networks enhances the entrepreneur's capability to tolerate uncertainty and risk. Collectivist societies may also be particularly conducive to obtaining social capital for new ventures. ${ }^{27}$

The flexibility in the enforcement of China's Employment Contract Law (ECL) provided Haier with an ability to quickly reduce its size from over 80,000 in 2012 to 60,000 staff in 2016 in order to implement Rendanheyi 2.0. While downzising in China is subject to some strict rules, the government has long supported the re-structuring of state-owned enterprises including mass layoffs ${ }^{28}$, and - crucially for innovating firms in China - Article 41 of the ECL specifically permits mass layoffs when a firm "switches production, introduces a major technical innovation or revises its business method". ${ }^{29}$ Likewise, Haier was able to shift the basis of remuneration from paying salaries towards remuneration based entirely on performance. Senior Haier managers in foreign subsidiaries in the United States and Europe state that their legal systems, as well as entrenched employment relationships in these countries, are incompatible with Rendanheyi 2.0 as practiced in China, which is why Haier had to make adaptations when introducing Rendanheyi in its foreign subsidiaries. Rendanheyi was most successfully transplanted by Haier to Russia, but the head of Haier's Russian operation said to us that it is not possible to have quite the same remuneration systems that Haier uses in China because "in Russia we have local law and local worker protection issues" and also because "it is quite difficult for some persons to understand why they should invest money when they join the company".

China's corporate governance systems also assisted in the introduction of Rendanheyi. The Haier Group and Zhang enjoyed considerable decision-making freedom thanks to the nature of the ownership structure. Although the Haier Group is under partial public ownership, it is technically a "collective" company, whereby its employees own the company. Haier's exact ownership stakes are typically not known, as the ownership of state-owned enterprises (SOEs) 
in China is often shrouded in secrecy and finding out who the real owners are, let alone the ownership percentage, is extremely difficult. ${ }^{30}$ In reality, the employees receive no dividends and do not even know how much they own - and crucially - the rank-and-file employees have negligible influence on the strategic direction of the firm. The real strategic power resides in a high-degree of strong, top-down leadership at Haier. Of course, this was also true at Steve Jobs' Apple or Bill Gates' Microsoft, and is presently the case at Alibaba, Xiaomei, Tencent, and other innovative firms.

Zhang's freedom to experiment with new management practices was additionally strengthened because the Chinese government signaled that Chinese firms should increase the rate of innovation. This was spelled out in the fifteen-year National Medium- and Long-Term Program for Science and Technology Development that focused on "indigenous innovation" and was issued by the State Council in February 2006. Furthermore, the Shandong provincial government specifically supported Haier's innovation drive. The Chinese central and provincial governments welcomed Haier's journey into uncharted waters without having to worry about the effects of massive layoffs on public opinion. So China's institutional context actually encouraged putting into place radical new management practices as part of the Rendanheyi platform.

\section{Organizational context}

The three categories of organizational context we identified are structure, leadership, and resources. We first discuss organizational structure, before describing the role of leadership and then resources, including organizational culture.

\section{Structure}


All of Haier's "reinventions" over more than three decades have been top-down driven, and have been initiated before many would have considered this "necessary" (i.e., Haier is wellknown for disrupting itself or cannibalizing its own cash flows). Doing this well requires an appropriate structure.

Haier's structure might both obstruct and stimulate innovative changes in management practices. Being originally a municipality-owned enterprise, the functional structure, with tight separation between units and departments, might prevent implementing new ideas and meeting user needs. At the same time, Haier's top-down, hierarchical structure helped Zhang Ruimin to effectively introduce and diffuse his new management approaches throughout the entire organization. Subsequently, Zhang Ruimin was able to adopt an energetic, visionary leadership style required to drive changes.

Organizations that thrive in a VUCA environment, make experimentation a way of organizational life. ${ }^{31}$ Zhang's strong hold on the company allowed him to keep experimenting and reinventing the company. From the 1980s onwards, Zhang took various steps to change the company structure and to mould the organizational culture. Already in 1989, Haier introduced the practice of "overall, every, control, and clear" (OEC), a Japanese-inspired practice to control "everything, everyone, and every day" in order to increase the accountability of all employees and to stimulate them to continually challenge ineffective work practices. Subsequently, Zhang started to slowly move from the traditional hierarchical and siloed structure into a project-based network structure. In 1999 Haier's organizational structure was entirely transformed into a matrix, consisting of four development divisions and six functional departments with greater decision-making autonomy. Between 1998 and 2002, Haier reportedly changed the organizational structure on more than forty occasions. Operating in a context characterized by frequent experimentation with structure made Haier more amenable to later structural changes. 


\section{Leadership}

By the mid-2000s, the Haier Group had become one of the leading white goods companies globally. But Zhang Ruimin believed that the VUCA environment was a great threat to the existence of traditional companies such as Haier. "When the world changes, we need to embrace change or we will be eliminated by the changing world", he noted on various occasions. Chairman Zhang's key concern was that Haier's successful expansion also reduced its flexibility and entrepreneurial spirit that was needed to tackle the volatile, uncertain, complex, and ambiguous forces that he observed. He told us that he observed a similar pattern in Silicon Valley: "When enterprises start they are agile, when they become bigger they become less flexible". Zhang concluded that Haier needed innovative management practices to strengthen the entrepreneurial spirit and user orientation.

Like many other Chinese executives, Zhang initially looked up to Western firms and consultants to emulate their management practices. He regularly travelled to the United States and Europe, visited Silicon Valley and consulted with senior executives at IBM and HP. By around 2005, Zhang initiated an HR transformation project in partnership with IBM, an IT transformation project in conjunction with HP and R\&D collaborations with universities such as MIT, among others. At the time, the introduction of performance-based compensation was quite novel for a large Chinese company. But the introduced performance management and communications practices did not move Haier nearly far enough towards Zhang's vision of empowering every employee. "The traditional methods only cater to the traditional era", he remarked.

Zhang thought that cutting edge management practices from some IT firms in Silicon Valley were not necessarily applicable to a global manufacturing company with 80,000 
employees. Conversely, he thought that no large conventional hierarchical firm in the West has yet come up with the sort of radical management practice that he envisaged for Rendanheyi. So he decided to experiment with introducing different management practices to bring his ideas into reality, looking for inspiration in traditional Chinese writings, management gurus such as Peter Drucker and new concepts such as quantum theory and "maker" culture. While experimenting with new practices, he was driven by an eclectic mix of ideas such as the concept of a "market chain" about connecting the company with the market, Peter Drucker's vision about the changing role of employees as "everybody should become their own CEO" and ancient Taoist ideas of Laozi about leadership. Consequently, Rendanheyi became a unique product of different traditions and influences that was essentially driven by one leader.

In February 2009, Zhang first proposed the introduction of ZZJYTs during a performance review for the previous month. Zhang experimented with different ZZJYT setups, not least because there was a perceived lack of collaboration between ZZJYTs. By the end of 2012, ZZJYTs and their market chains were grouped into 'communities of common interests', which were typically led by the most influential ZZJYTs in the chain. But ZZJYTs did not go far enough towards Zhang's vision for Rendanheyi and Zhang finally initiated the shift from ZZJYT to xiaowei in 2013.

The xiaowei came close to fulfilling Zhang's vision of empowering every employee, but it also conformed with Zhang's acceptance of the ancient ideas of Laozi about true leadership. While Haier uses many different communications channels to convey Zhang's Rendanheyi vision to the employees - the "Haier University" training, an internal newsletter, a monthly "entrepreneurs cafe'" and Zhang's personal book recommendations for employees Zhang believes in Laozi's idea that ultimately "supreme leadership is to make the leader invisible". The xiaowei make autonomous decisions without the involvement of the headquarter, like the invisible hand of the market once described by Adam Smith. Quite visibly 
though, without Zhang's enormous leadership in terms of designing and implementing Rendanheyi, the new management practice would not exist, so we would argue that leadership is the most important factor.

\section{Resources}

To complement the changes to the organizational structure, Zhang developed a new corporate culture to support the company's shift towards responsiveness and customer orientation. To encourage simultaneous internal cooperation and competition among the company units, Haier's corporate culture emphasized internal reputation and performance. Backed up by appropriate performance management systems, the company emphasized that the more productive and customer-oriented employees are, the more decision-making autonomy and greater rewards they will receive. The new corporate culture was understandably more receptive to the radical changes in organizational practices in the mid-2000s.

But beyond employing the organizational culture as a resource, the introduction of a new management system required resources such as consultancy fees, new IT systems and staff training. More importantly, the performance outcomes of Rendanheyi were totally unknown and unsuccessful implementation could become a major drain on the company's finances. However, Zhang Ruimin suggested that Rendanheyi would proceed even if revenues and profits showed signs of weakening.

Fortunately Chairman Zhang did not have to worry about resources or the potential impact on investors when he introduced his new management system in 2005. Haier's revenues in the mid-2000s were soaring, having quadrupled from ca. 27 RMB billion in 1999 to 103 RMB billion in 2005. And the Haier Group was under partial public ownership, freeing the company from delivering consistent financial returns. 
The freedom to allocate resources distinguished Haier from Western competitors. Indeed, Zhang Ruimin told us that he specifically discussed the idea of introducing Rendanheyi with senior management of a very large US multinational firm and he was reportedly told that “we cannot do it [introduce Rendanheyi] because we need to play by Wall Street rules". On another occasion, a group of visiting European managers from several well-known large enterprises accused Haier of fabricating a "Trompe-l'œil" with their ZZJYTs and communities of interest, suggesting that such radically innovative practices would be "impossible to implement". A focus on quarterly results and steady revenues keeps American and European companies from even contemplating the sort of changes that Rendanheyi requires. In contrast, Haier's resources allowed Zhang to embark on a radical new management innovation, shifting the firm from a traditional manufacturer towards an agile online platform driven firm, without any guarantee that this turnaround would actually enhance organizational performance.

\section{Lessons for management innovators}

The Haier Rendanheyi case produces four key lessons for management innovation. First, it is clear that one good response to a high VUCA world is management innovating, i.e. the creation of innovative management systems. We showed how Rendanheyi constituted just such a response for the Haier Group. The Haier case is quite significant, since this is not a company from the buzzing IT sector in Silicon Valley or the innovative biotech sector in Britain's Silicon Fen. The white goods industry is traditionally a mature, slow-moving and low-profit manufacturing sector. Yet an environment with high VUCA is challenging this sector too, and the Haier example illustrates the necessity as well as the opportunity for established companies to invent novel management systems in response. 
The second lesson revolves around how Haier experimented with Rendanheyi. The case study demonstrates that experimentation is a sine qua non for success in a VUCA environment. In particular, the Haier case demonstrates that leadership may eventually be the single most important contextual factor for making management innovation work. Furthermore, the management innovation seemed to co-evolve with the ideas and experiences of Haier's CEO. This suggests that those leaders that can actually learn from experiments are best placed to make management innovation work.

Third, we presented an extended process model of management innovation, which managers in both emerging and developed countries can apply. The four-stage process model, illustrated in Figure 1, describes each of the stages managers go through when undertaking management innovation, with the internal and external contexts influencing all four stages. Managers must carefully consider competitive, technological and institutional constraints when engaging in a new management innovation, while the three organizational contextual factors of structure, leadership and resources act as enables or levers for management innovating. Clearly the relative importance of internal and external contexts varies from one episode to the next, as emphasized by Zhang Ruimin: "[B]oth matter... the first big transformation of Haier was based on external factors, as we knew that the market was going to become much more competitive, but the next transformation was based on a fear that we had, or would, become much too bureaucratic, and so we needed to combat the internal tendency."

Fourth, we suggest that managers should align the nature of management innovations they create, and how these are created, to the six environmental categories in our model, in line with the Haier case but also following other successful management innovators throughout history. Where leadership in an organization is strong and charismatic, a top-down creation process is more viable, which is how GM came up with the divisional M-form. With slack resources, organizations should attempt to undertake more management innovation, as GE has 
demonstrated throughout its history with stretch goals, Six Sigma, and the strategic business unit to mention but a few. Organizations that want to be more effective management innovators have to build structures that allow for more experimentation, as Procter and Gamble did with Connect-and-Develop. ${ }^{32}$ Furthermore managers must align their attempts at management innovating to what is possible in their institutional environment, Toyota's lean manufacturing being a great example as noted earlier. Finally, they should increase efforts at management innovation when technological change is frequent and when there is intense competitive pressure, which was part of the reasoning behind Samsung's co-opetition model mentioned earlier.

\section{Discussion and conclusion}

The main contributions of this article are threefold: 1) demonstrating how the internal and external contexts mattered for the creation of Rendanheyi to allow Haier to deal with a high VUCA world; 2) drawing lessons from Haier's experimentation process for other firms; 3) providing an improved explanation of how new management innovations are created.

For the creation of Rendanheyi, leadership was the most important contextual factor and our model extends the literature on the role of leadership in management innovation ${ }^{33}$ by providing a detailed description of how strong leadership can drive the development and implementation of management innovation. Yet we suggest that leadership would not have been enough to drive Rendanheyi through, if the other contextual factors were not aligned and pushed in the same direction. In general terms, strong leadership does not always have to be the most important factor for every single management innovation. Looking back at management innovations, for instance, the initial development of innovations like the balanced scorecard at 
Analog Devices and scenario planning at Shell was neither initiated nor driven by top management. ${ }^{34}$

The complexities and uncertainties of the VUCA world are driving firms like Haier to create management innovations that are appropriate to the context in which they operate. This article shows specifically how rapid/timely responses to deal with VUCA lead to context dependent management innovations created by emerging market firms like Haier. Rendanheyi allows Haier to both connect better to customers and create more internal cohesion, without sacrificing scale advantages, due to technology deployment. Our model suggests that managers must carefully consider the specific context within which they operate before introducing a novel management innovation.

Some questions on the future development of Rendanheyi are unresolved, as the transfer of Rendanheyi to Haier's foreign affiliates, other companies and other national contexts will be challenging. The challenges Haier faces in the implementation of Rendanheyi are, to some extent, archetypical of breakthrough innovations. It is well documented that key stakeholders are often cautious and even unwilling to adopt/participate in breakthrough innovations for a myriad of reasons. ${ }^{35}$ More fundamentally, as we have seen, there are cultural and legal impediments that limit Rendanheyi's applicability in other institutional contexts. Rendanheyi may not work as well, or not at all in other countries and, in fact, the implementation of Rendanheyi has been very limited in Haier's foreign affiliates. Haier executives still hope to eventually transfer Rendanheyi to Haier's global affiliates, but the takeover of GE's white goods division may render this objective even more difficult.

Within those affiliates where Rendanheyi has been fully introduced, Haier also needs to consider some crucial issues going forward, including how organization-wide process innovations can be implemented by semi-autonomous xiaowei, given that user-facing xiaowei are obsessed with product innovations with relatively quick payoffs and are less concerned with 
longer-term collective interests of the Haier Group. As the Haier Group is progressively diluting its ownership stakes in the xiaowei, Haier must also consider how successful xiaowei can be prevented from fully disengaging themselves from the Haier Group organization. Although, one possible future for Haier would be to transform into a "flotilla" model away from the "ocean liner", as Zhang Ruimin has already indicated that "we may be entering the era of losing control" in the quest to serve customers better, and to continue to unleash talent.

Future research will need to further investigate to what extent Rendanheyi and other context-specific management innovations from emerging countries are transferable across national borders and organizational boundaries. There is much evidence that the transfer of organizational innovations across institutional contexts often fails. The failed or incomplete transfer of management innovations from Japan to the West and the mixed success of novel hierarchy-free organizational forms such as holacracy should serve as a warning to managers. ${ }^{36}$ As we have seen, China's institutional context is particularly conducive to Rendanheyi. There is no written manual for introducing Rendanheyi and, in fact, the ambiguity and vagueness of the precise contents of Rendanheyi is typical of most Chinese management models, as Chinese organizations tend to develop broad and imprecise strategies that are short on details and vague on the specific steps to implement them. ${ }^{37}$ Furthermore, Rendanheyi took a long time to develop into what it is today, and compared to key historical management innovations, only the making of Toyota's lean production platform has taken as long. ${ }^{38}$ Haier's long experimentation with Rendanheyi may have been an important reason why the practice was successfully implemented within the company, since the practice was moulded by the specific experiences of the company and Haier employees gradually got used to assuming greater management responsibilities. Therefore, the Rendanheyi case suggests that organizations must be cautious before cutting and pasting radically innovative processes and mechanisms to obtain the same goals. Nonetheless, 
some elements of Rendanheyi could well be emulated by companies around the world and this case will surely inspire managers and academics working with management innovation. 
TABLE 1. Key characteristics of Rendanheyi and Rendanheyi 2.0

\begin{tabular}{|l|l|l|}
\hline Organizational structure & $\begin{array}{l}\text { Rendanheyi (2005-2014) } \\
\text { Organizational hierarchy with } \\
\text { increasing autonomy for } \\
\text { corporate units - moving from } \\
\text { strategic business units to } \\
\text { micro-divisions called ZZJYT }\end{array}$ & $\begin{array}{l}\text { Collection of independent } \\
\text { micro-enterprises called }\end{array}$ \\
\hline xiaowei
\end{tabular}

TABLE 2. Simplified organizational structure of Rendanheyi 2.0

\begin{tabular}{|l|l|l|}
\hline Tier 1 xiaowei & $\begin{array}{l}\text { Type of organization } \\
\text { user-facing micro-enterprises }\end{array}$ & $\begin{array}{l}\text { Main function } \\
\text { design, develop, manufacture and } \\
\text { distribute products and services }\end{array}$ \\
\hline Tier 2 xiaowei & node micro-enterprises & $\begin{array}{l}\text { provide products and services to } \\
\text { Tier 1 micro-enterprises }\end{array}$ \\
\hline Corporate headquarter & corporate services platforms & $\begin{array}{l}\text { provide services to Tier 1 and Tier } \\
2 \text { micro-enterprises, set the } \\
\text { strategic direction for the entire } \\
\text { organization, allocate resources }\end{array}$ \\
\hline
\end{tabular}


FIGURE 1. Management innovating model with contextual factors

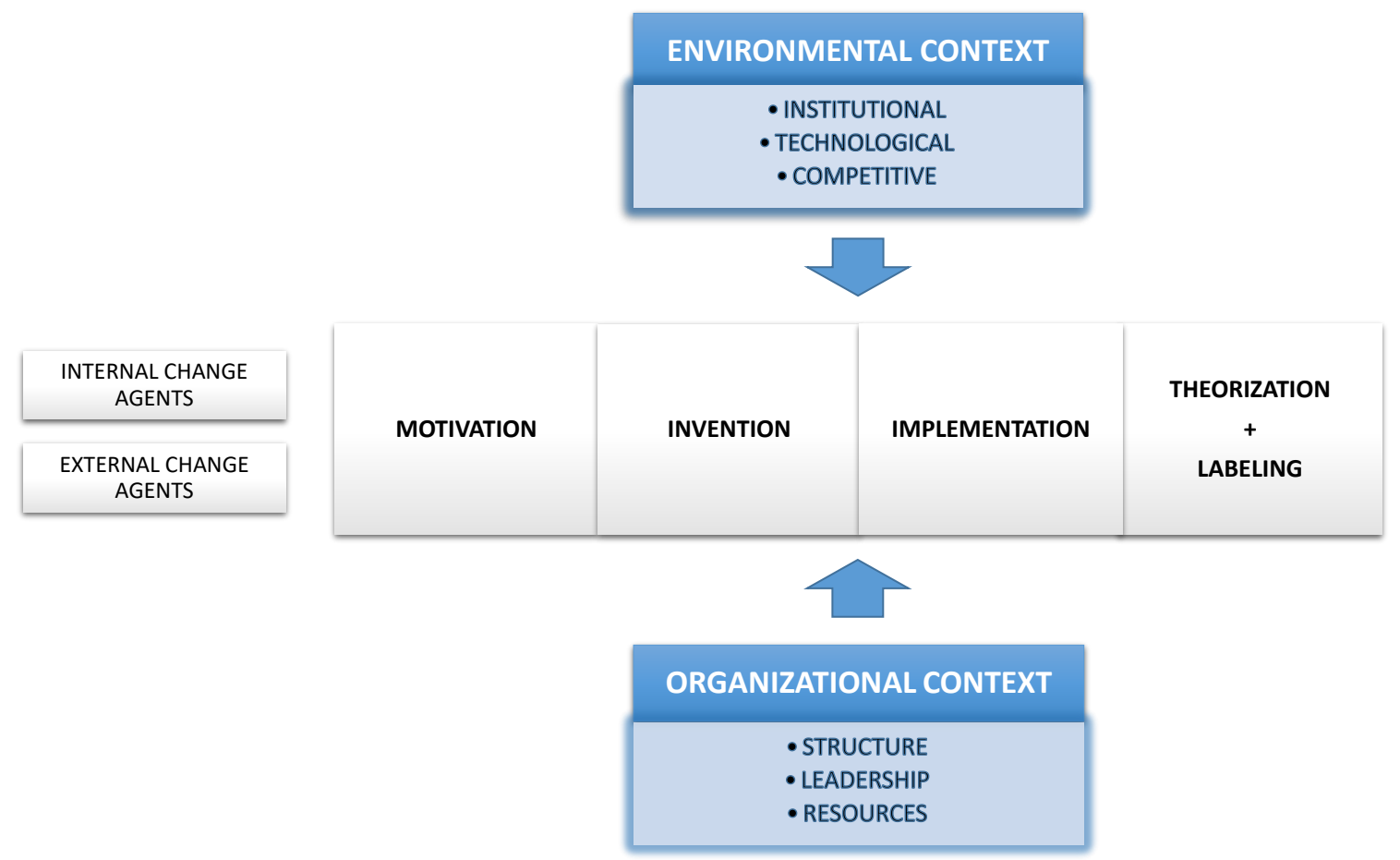




\section{Notes}

The authors would like to thank the special issue editors and the anonymous reviewers for their helpful comments throughout the review process. We are thankful to the Haier Group for allowing us full access to their sites and employees. Finally, we are also very grateful for our exchanges with Bill Fischer, who commented on a previous draft and provided us with some valuable factual observations.

${ }^{1}$ The acronym VUCA has been utilized to label an environment which makes it hard for executives to predict and adjust to change, and which requires novel enterpreneurial approaches and managerial capabilities. On VUCA, see N. Bennett and G. J. Lemoine, "What a Difference a Word Makes: Understanding Threats to Performance in a VUCA World," Business Horizons, 57 (2014): 311-317. This challenging environment has been referred to by different names, for example, the term TUNA (turbulence, uncertainty, novelty, ambiguity) has been used by R. Ramírez and A. Wilkinson, Strategic reframing: The Oxford scenario planning approach (Oxford University Press, Oxford, 2016).

${ }^{2}$ See, for example, H. G. Barkema, X. P. Chen, G. George, Y. Luo, and A. S. Tsui, "West Meets East: New Concepts and Theories," Academy of Management Journal, 58/2 (2015): 460-479; J. B. Barney and S. Zhang, "The Future of Chinese Management Research: A Theory of Chinese Management versus a Chinese Theory of Management," Management and Organization Review, 5/1 (2009): 15-28.

${ }^{3}$ J. Birkinshaw, G. Hamel, and M. J. Mol, "Management innovation," Academy of Management Review, 33/4 (2008): 825-845.

${ }^{4}$ M. Udagawa, "The Development of Production Management at the Toyota Motor Corporation," Business History, 37 (1995): 107-119. 
${ }^{5}$ The early development of Rendanheyi, including the ZZJYTs, has been described in B. Fischer, U. Lago and F. Liu, Reinventing Giants - How Chinese Global Competitor Haier has Changed the Way Big Companies Transform (Jossey-Bass, San Francisco CA, 2013); M. W. Meyer, L. Lu, J. Peng and A. S. Tsui, "Microdivisionalization: Using Teams For Competitive Advantage," Academy of Management Discoveries 3/1 (2017): 3-20. However, Rendanheyi has evolved since their publication and the lessons learned from ZZJYTs are not necessarily applicable to the current micro-enterprises which are organized somewhat differently.

${ }^{6}$ For an overview, see F. Damanpour, "Footnotes to Research on Management Innovation," Organization Studies, 35/9 (2014): 1265-1285.

${ }^{7}$ Birkinshaw, Hamel, and Mol (2008), op. cit.; M. J. Mol and J. Birkinshaw, Giant Steps in Management: Innovations that Change the Way You Work (Prentice-Hall, New York, 2008); M. J. Mol and J. Birkinshaw, "The Role of External Involvement in the Creation of Management Innovations,” Organization Studies, $35 / 9$ (2014): 1287-1312.

${ }^{8}$ Several contextual factors have been mentioned in the literature. For instance, F. Damanpour and D. Aravind, "Managerial innovation: Conceptions, processes, and antecedents," Management and Organization Review, 8 (2012): 423-454 emphasize internal organizational factors, especially the attitude of managers, as well as external factors in the adoption of management innovations. Similarly, elements like outside competition, technological innovation, and organizational resources are central to the analysis in A. Ganter and A. Hecker, "Configurational paths to organizational innovation: qualitative comparative analyses of antecedents and contingencies," Journal of Business Research, 67 (2014): 1285-1292. Our paper goes beyond those works by offering a complete set of contextual factors, rather than a sub selection, and applying it specifically to the innovation creation process (not later adoption). 
${ }^{9}$ See, for example, S. M. Ansari, P. C. Fiss, and E. J. Zajac, "Made to fit: How practices vary as they diffuse," Academy of Management Review, 35 (2010): 67-92; M. T. Kennedy and P. C. Fiss, "Institutionalization, Framing, and Diffusion: The Logic of TQM Adoption and Implementation Decisions among US Hospitals," Academy of Management Journal, 52 (2009): 897-918.

${ }^{10}$ Birkinshaw, Hamel, and Mol (2008), op. cit., and commented upon by Damanpour and Aravind (2012), op. cit.

${ }^{11}$ Udagawa (1995), op. cit., and Mol and Birkinshaw (2008), op. cit.

${ }^{12}$ On Samsung's co-opetition model, see J. Song, K. Lee and T. Khanna, “Dynamic Capabilities at Samsung: Optimizing Internal Co-Opetition," California Management Review, 58/4 (Summer 2016): 118-140.

${ }^{13}$ C. Hampden-Turner and F. Trompenaars, Seven Cultures of Capitalism (New York: Doubleday, 1993) provides excellent insights on the importance of the Japanese culture in the development of lean manufacturing.

${ }^{14}$ Song, Lee, and Khanna (2016), op.cit.

${ }^{15}$ Birkinshaw, Hamel, and Mol (2008), op. cit., p. 833. A more recent extension of the model (Mol and Birkinshaw 2014, op. cit.) likewise does not discuss the context in which innovating takes place, instead focusing on where internal and external change agents obtain the knowledge required for innovating.

${ }^{16}$ M. F. Guillen, Models of management: Work, authority, and organization in a comparative perspective (University of Chicago Press, Chicago, 1994).

${ }^{17}$ R. W. Zmud, "Diffusion of modern software practices: Influence of centralization and formalization," Management Science, 28 (1982): 1421-1431. 
${ }^{18}$ S. Nickell, D. Nicolitsa and M. Patterson, "Does Doing Badly Encourage Management Innovation?," Oxford Bulletin of Economics \& Statistics, 63 (2001): 5-28.

${ }^{19}$ D. Rigby, "Management Tools and Techniques: A Survey," California Management Review, 43/2 (2001): 139-160.

${ }^{20}$ E. S. Steinfeld and T. Beltoft, "Innovation Lessons from China," MIT Sloan Management Review, Summer (June 2014): 49-55.

${ }^{21}$ Zhang Ruimin quoted in L. Sharp Paine, "Haier Group (A)”, Harvard Business School case 398-101, July 27, 2001.

${ }^{22}$ Yang Mianmian quoted in T. Palepu, T. Khanna and I. Vargas, "Haier: Taking a Chinese company global”, Harvard Business School case 9-706-401, August 25, 2006.

${ }^{23}$ International Monetary Fund, World Economic Outlook database (accessed May 4, 2017).

${ }^{24}$ D. Tapscott, Wikinomics - How Mass Collaboration Changes Everything (Tantor Media, Old Saybrook CT, 2006); J. Rifkin, The Third Industrial Revolution: How Lateral Power is Transforming Energy, the Economy, and the World (Palgrave, New York, 2011).

${ }^{25}$ Y. Zhou, "Letter to the editor - Haier's management model of Rendanheyi: From sea to iceberg," Management and Organization Review 13/3 (2017): 687-688 explains the philosophy behind these platforms.

${ }^{26}$ C. He, J. Lu and H. Qian, “Entrepreneurship in China,” Small Business Economics (2018), doi: 10.1007/s11187-017-9972-5.

27 E. U. Weber and C. Hsee, "Cross-cultural differences in risk perception, but cross-cultural similarities in attitudes towards perceived risk," Management Science, 44/9 (1998): 12051217; U. Stephan and L. M. Uhlaner, "Performance-based vs socially supportive culture: a 
cross-national study of descriptive norms and entrepreneurship," Journal of International Business Studies 41/8 (2010): 1347-1364.

${ }^{28}$ X. Dong and L. C. Xu, "Labor restructuring in China: Toward a functioning labor market," Journal of Comparative Economics, 37/2 (2009): 287-305.

${ }^{29}$ K. Jones, Faegre Baker Daniels and Practical Law China, "Managing redundancies and mass layoffs: China”, Practice Notes, Resource ID 3-567-8876, Thomson Reuters (2018).

${ }^{30}$ G. H. Jefferson, “China's state enterprises: public goods, externalities, and Coase,” American Economic Review, 88/2 (1998): 428-432 reported that ambiguous and widely dispersed ownership structures is one of the key characteristics of SOEs. Similarly, J. Guo, S. Hou, G. Smith and S. Martinez-Pacheco, "Chinese outward direct investment," in: J. Garrick (ed.) Law and policy for China's market socialism (London: Routledge, 2012: 132) noted that "It is often difficult to find out precisely who are the 'real owners' of China's SOEs".

${ }^{31}$ Bennett and Lemoine (2014), op. cit.

${ }^{32}$ On these and other historical examples of management innovations, see Mol and Birkinshaw (2008), op. cit. We think that the academic literature would benefit from rigorous fieldwork to look into the model presented in our paper. This could well take the approach of a field quasi-experiment, where academic researchers work with a company where a new practice is created and rolled out in one part of the organization, while the other part does not undergo this same treatment. Such an approach is unusual, but can be found in some earlier work by people like Andrew Van De Ven. A good summary of this approach is found in A. H. Van De Ven, Engaged scholarship: A guide for organizational and social research (Oxford: Oxford University Press, 2007). Alternatively, survey research can be used to determine which contextual factor matters most in the adoption, not so much the creation, of management innovations. 
${ }^{33}$ I. G. Vaccaro, J.J.. Jansen, F. A. Van Den Bosch and H. W. Volberda. "Management innovation and leadership: The moderating role of organizational size," Journal of Management Studies, 49/1 (2012): 28-51.

${ }^{34}$ See Mol and Birkinshaw (2008), op. cit. Likewise, the further development of management innovations may not be initiatied by top management, as was the case with the recent refinement of scenario planning by strategy experts. Ramírez and Wilkinson (2016), op. cit.

${ }^{35}$ Stakeholders may be reluctant to adopt the innovation because of lack of knowledge and agreement about how the different parts of the innovation fit together. During the early stage there is usually a great deal of confusion and experimentation and some stakeholders groups may prefer to wait until a consensus emerges. See, for example, R. D. Dewar and J. E. Dutton, "The adoption of radical and incremental innovations: An empirical analysis," Management Science, 11/32 (1986): 1422-1433; P.-T. Chen and S.-C. Kuo, "Innovation resistance and strategic implications of enterprise social media websites in Taiwan through knowledge sharing perspective," Technological Forecasting and Social Change, 118 (2017): 55-69.

${ }^{36}$ P. Lillrank, "The transfer of management innovations from Japan," Organization Studies, 16/6 (1995): 971-989; E. Bernstein, J. Bunch, N. Canner and M. Lee, "Beyond the holacracy hype," Harvard Business Review, 94/7-8 (2016): 38-49.

${ }^{37}$ X. C. Huang, "The influence of national culture, history and institution on strategic management in Chinese firms: A complexity based perspective," International Journal of Business Studies, 17/1 (2009): 1-18 noted that Chinese executives put a strong emphasis on experimentation which explains why malleable strategies are often put forward while critical implementation issues are left unresolved. On the one hand, this is chiefly due to the fluid and highly dynamic business environment that requires companies to favor broad strategies that provide them with a wide array of options and allow them to experiment and adapt. On the other hand, there are cultural (holistic view and dialectical thinking) and historical reasons 
that made Chinese organizations more reflexive in order to absorb unexpected external changes and continuously morph to cope with heightened complexity and uncertainty in the business environment.

${ }^{38}$ Mol and Birkinshaw (2008), op. cit. 